\title{
Can one or two high doses of oral vitamin D3 correct insufficiency in a non-supplemented rheumatologic population?
}

\author{
D. Stoll • J. Dudler • O. Lamy • D. Hans • M. A. Krieg • \\ B. Aubry-Rozier
}

Received: 8 September 2011 / Accepted: 16 February 2012/Published online: 17 March 2012

(C) International Osteoporosis Foundation and National Osteoporosis Foundation 2012

\begin{abstract}
Summary We evaluated the effectiveness of supplementation with high dose of oral vitamin D3 to correct vitamin D insufficiency. We have shown that one or two oral bolus of 300,000 IU of vitamin D3 can correct vitamin D insufficiency in $50 \%$ of patients and that the patients who benefited more from supplementation were those with the lowest baseline levels.

Introduction Adherence with daily oral supplements of vitamin D3 is suboptimal. We evaluated the effectiveness of a single high dose of oral vitamin D3 (300,000 IU) to correct vitamin D insufficiency in a rheumatologic population.

Methods Over 1 month, 292 patients had levels of 25 $\mathrm{OH}$ vitamin $\mathrm{D}$ determined. Results were classified as: deficiency $<10 \mathrm{ng} / \mathrm{ml}$, insufficiency $\geq 10$ to $30 \mathrm{ng} / \mathrm{ml}$, and normal $\geq 30 \mathrm{ng} / \mathrm{ml}$. We added a category using the IOM recommended cut-off of $20 \mathrm{ng} / \mathrm{ml}$. Patients with deficient or normal levels were excluded, as well as patients already supplemented with vitamin D3. Selected
\end{abstract}

D. Stoll $\cdot$ O. Lamy $\cdot$ D. Hans $\cdot$ M. A. Krieg $\cdot$ B. Aubry-Rozier Center for Bone Diseases, University Hospital of Lausanne, Lausanne, Switzerland

J. Dudler $\cdot$ B. Aubry-Rozier

Division of Rheumatology, University Hospital of Lausanne,

Lausanne, Switzerland

J. Dudler

Department of Rheumatology,

HFR Fribourg-Fribourg Cantonal Hospital,

Fribourg, Switzerland

D. Stoll $(\bowtie)$

Lausanne University Hospital (CHUV) - DAL,

Avenue Pierre Decker 4,

1011 Lausanne, Switzerland

e-mail: delphine.stoll@chuv.ch patients (141) with vitamin D insufficiency (18.5 ng/ml (10.229.1) received a prescription for 300,000 IU of oral vitamin D3 and were asked to return after 3 (M3) and 6 months (M6). Patients still insufficient at M3 received a second prescription for 300,000 IU of oral vitamin D3. Relation between changes in 25-OH vitamin D between M3 and M0 and baseline values were assessed.

Results Patients (124) had a blood test at M3. Two (2\%) had deficiency $(8.1 \mathrm{ng} / \mathrm{ml}(7.5-8.7))$ and $50(40 \%)$ normal results (36.7 ng/ml (30.5-5.5)). Seventy-two (58\%) were insufficient (23.6 $\mathrm{ng} / \mathrm{ml}(13.8-29.8))$ and received a second prescription for 300,000 IU of oral vitamin D3. Of the 50/124 patients who had normal results at M3 and did not receive a second prescription, $36(72 \%)$ had a test at M6. Seventeen (47\%) had normal results $(34.8 \mathrm{ng} / \mathrm{ml}(30.3-42.8))$ and $19(53 \%)$ were insufficient $(25.6 \mathrm{ng} / \mathrm{ml}(15.2-29.9))$. Of the $72 / 124$ patients who receive a second prescription, $54(75 \%)$ had a test at M6. Twenty-eight (52\%) had insufficiency $(23.2 \mathrm{ng} / \mathrm{ml}(12.8-$ 28.7)) and $26(48 \%)$ had normal results $(33.8 \mathrm{ng} / \mathrm{ml}(30.0$ 43.7)). At M3, $84 \%$ patients achieved a $25-\mathrm{OH}$ vitamin D level $>20 \mathrm{ng} / \mathrm{ml}$. The lowest the baseline value, the highest the change after 3 months (negative relation with a correlation coefficient $r=-0.3, p=0.0007$ ).

Conclusions We have shown that one or two oral bolus of 300,000 IU of vitamin D3 can correct vitamin D insufficiency in $50 \%$ of patients.

Keywords Single high dose of vitamin D · Vitamin D insufficiency · Vitamin D oral supplementation

\section{Introduction}

Vitamin D insufficiency is highly prevalent [1]. There is a large amount of evidence that with a daily oral intake of 700 to 
1,000 IU of vitamin D3, the often-recommended serum level of $20-30 \mathrm{ng} / \mathrm{ml}$ of $25-\mathrm{OH}$ vitamin D is usually achieved and up to $20 \%$ of falls and fractures are prevented [2-6]. In epidemiological studies, this recommended level has been associated with decreased cardiovascular, oncologic, and rheumatologic diseases [7, 8]. However, several recent works also question these findings and suggest that we have been overestimating vitamin D insufficiency using high cut-offs (such as $30 \mathrm{ng} / \mathrm{ml}$ ) and its consequences[9-11].

Adherence with daily oral supplements of vitamin D3 is suboptimal, with $50-75 \%$ of the population on oral daily vitamin D supplementation still exhibiting vitamin D insufficiency depending of the dose administered $[12,13]$. If vitamin D supplementation is taken less than $80 \%$ of the time, the benefits against fractures and falls are lost [12].

We elected to evaluate the effectiveness of supplementation with a single high dose of oral vitamin D3 (300,000 UI) to correct vitamin D insufficiency, a simple procedure that has gained wide acceptance in Switzerland despite controversy and the lack of any formal demonstration of effectiveness.

\section{Methods}

Study design and subjects

Over 1 month (November 2009), 292 consecutive patients attending our Rheumatology Outpatient Clinic at the University Hospital of Lausanne (latitude $46.52^{\circ} \mathrm{N}$ ) had their blood level of $25-\mathrm{OH}$ vitamin D measured. $25-\mathrm{OH}$ vitamin $\mathrm{D}$ levels were determined using radioimmunologic assay with extraction (25-hydroxyvitamin D ${ }^{125}$ I RIA Kit, DiaSorin ${ }^{\circledR}$ ): the first step involves rapid extraction of $25-\mathrm{OH}$ vitamin $\mathrm{D}$ and other hydroxylated metabolites from serum with acetonitrile. Following extraction, the treated sample is then assayed using equilibrium RIA procedure based on an antibody with specificity to $25-\mathrm{OH}$ vitamin $\mathrm{D}$.

Patients were classified into one of the following categories according to their $25-\mathrm{OH}$ vitamin D level: deficient with levels $<10 \mathrm{ng} / \mathrm{ml}(<25 \mathrm{nmol} / \mathrm{l})$, insufficient with levels $\geq 10$ to $<30 \mathrm{ng} / \mathrm{ml}$ ( $\geq 25$ to $75 \mathrm{nmol} / \mathrm{l}$ ), and normal with levels $\geq 30 \mathrm{ng} / \mathrm{ml}(\geq 75 \mathrm{nmol} / \mathrm{l})$. These definitions were based on a widely recognized definition of insufficiency and deficiency [8]. They are not exactly the same as those used in the recent Endocrine Society and Institute of Medicine (IOM) recommendations $[14,15]$. We then a posteriori added a category using the IOM recommended cut-off of $20 \mathrm{ng} / \mathrm{ml}$ [14].

For the present study, only patients with vitamin $\mathrm{D}$ insufficiency $(\geq 10 \mathrm{ng} / \mathrm{ml}$ to $<30 \mu \mathrm{g} / \mathrm{l})$ were considered. Patients with deficient or normal levels were excluded, as well as patients already supplemented with daily oral vitamin D3 or who had received a single high dose of oral or intramuscular vitamin D3 within the previous 6 months.
At baseline, all selected patients received a prescription for a single high dose of 300,000 IU of oral vitamin D3 (Vitamin D3 Streuli ${ }^{\circledR} 1 \mathrm{ml}$, Streuli Pharma SA, 8730 Uznach, Switzerland) for the non-supervised administration of vitamin D3. No guidance was given on how to take the vitamin $\mathrm{D}$. They then were asked to return after 3 (M3) and 6 months (M6) for a new determination of their 25-OH vitamin D levels. Patients still insufficient $(\geq 10 \mathrm{ng} / \mathrm{ml}$ to $<30 \mu \mathrm{g} / \mathrm{l})$ at $\mathrm{M} 3$ received a second prescription for another single high dose of 300,000 IU of oral vitamin D3 (Vitamin D3 Streuli ${ }^{\circledR} 1 \mathrm{ml}$ ). Patients with deficiency at M3 were excluded from further follow-up, as they were administered either higher or intramuscular supplementation of vitamin D3.

This study is aligned with the Lausanne University Hospital Ethics committee. No outside funds were necessary. All patients were orally informed and oral consent was mandatory but no written informed consent was signed.

\section{Statistical analysis}

Relation between changes in 25-OH vitamin D between M3 and $\mathrm{M} 0$ and baseline values and relation between changes between M6 and M3 and M3 values were assessed by linear regression with statistical significance for $p$ value $<0.05$. All analyses were performed using Stata 12.0 statistical software (Stata Corp, College station, TX, USA).

\section{Results}

Two hundred ninety-two patients had their level of 25-OH vitamin D determined in November 2009 [13]. The details of the 25-OH vitamin D results of the total sample of the 292 patients have been published recently [13]. Briefly, $7 \%$ were deficient, $79 \%$ insufficient, and $14 \%$ had normal results. We excluded 124 patients for the present analysis, 20 patients who had previously received a single dose of $300,000 \mathrm{IU}$ of vitamin D3 within the preceding 6 months and 104 patients who were currently taking daily oral vitamin D3 supplements. Of the remaining 168 patients, 16 patients had levels of $<10 \mathrm{ng} / \mathrm{ml}$ and 11 patients had levels of $\geq 30 \mathrm{ng} / \mathrm{ml}$. One hundred forty-one remaining patients $(84 \%)$ presented with vitamin D insufficiency ( 84 patients with levels of $\geq 10$ to $<20 \mathrm{ng} / \mathrm{ml}$ and 57 patients with levels of $\geq 20$ to $<30$ $\mathrm{ng} / \mathrm{ml})$. Patients' characteristics are in the Table 1.

All patients were given a prescription for a single high dose of $300,000 \mathrm{IU}$ of oral vitamin D3. Figures 1 and 2 give the flow of the patients and the main findings at months 3 and 6 .

Vitamin D levels at month 3 (M3)

One hundred and twenty-four patients $(88 \%)$ returned to our Rheumatology Clinic at 3 months to have their $25-\mathrm{OH}$ 
Table 1 Characteristics of the 141 insufficient patients at baseline

\begin{tabular}{lll}
\hline & Mean \pm SD & Range \\
\hline Age (years) & $49.2 \pm 13.1$ & $17-84$ \\
BMI $\left(\mathrm{kg} / \mathrm{m}^{2}\right)$ & $26.4 \pm 5.5$ & $17-42$ \\
& Percentage & \\
Inflammatory disease & $84 \%$ & \\
Degenerative disease & $16 \%$ & \\
Osteoporosis & $5 \%$ & \\
\hline
\end{tabular}

vitamin D serum levels re-measured. Their demographic characteristics (mean age 49 years old [range 17-84], 65\% women) did not differ from the original subject sample.

Their mean serum level of $25-\mathrm{OH}$ vitamin $\mathrm{D}$ had increased to $28.6 \mathrm{ng} / \mathrm{ml}$ (range 7.5-56.5), and 50/124 (40\%) now had levels falling within the normal range (mean 25$\mathrm{OH}$ vitamin D $36.7 \mathrm{ng} / \mathrm{ml}$ [range 30.5-56.5]). Nevertheless, despite high dose supplementation, 58\% (72/124) still suffered from vitamin D insufficiency (mean 25-OH vitamin D $23.6 \mathrm{ng} / \mathrm{ml}$ [range 13.8-29.8]) and 2 (2\%) even had evolved to frank deficiency (25-OH vitamin D levels of 7.5 and $8.7 \mathrm{ng} / \mathrm{ml}$, respectively). All insufficient patients received a second prescription for another single high dose of 300,000 IU of oral vitamin D3. The two patients with deficiency at 3 months were excluded from further analysis.

Vitamin D levels at month 6 (M6)

Of the 122 remaining patients who were either vitamin D normal or insufficient at 3 months, 90 were available at 6 months for a final evaluation: 54 of the $72(75 \%)$ patients are still insufficient at M3, and 36 of the $50(72 \%)$ patients have normal levels at M3.

Among the 54 initially (M0 and M3) insufficient patients, 26 (48\%) now had normal levels of 25-OH vitamin D (mean $33.8 \mathrm{ng} / \mathrm{ml}$, range $30.0-43.7)$, while $28(52 \%)$ remained

Fig. 1 Effect of 1-2 high dose (s) of vitamin $\mathrm{D} 3$ on patients with insufficiency insufficient (mean 25-OH vitamin D serum level $23.2 \mathrm{ng} / \mathrm{ml}$ [range 12.8-28.7]). None were deficient.

Of the 36 patients who had normalized their serum vitamin D levels by 3 months after a single high dose of 300,000 IU of vitamin D3 and did not receive a second prescription, 47\% (17/36) still had normal levels at 6 months (mean 25-OH vitamin D serum level $34.8 \mathrm{ng} / \mathrm{ml}$ [range $30.3-42.8])$, while $53 \%(19 / 36)$ were again within the insufficiency range (mean $25-\mathrm{OH}$ vitamin D serum level $25.6 \mathrm{ng} / \mathrm{ml}$ [range 15.2-29.9]). None were deficient.

At M3, 84\% (104/124) patients achieved a 25-OH vita$\min \mathrm{D}$ level $>20 \mathrm{ng} / \mathrm{ml}$. Of those who received only one high dose of vitamin D3 at baseline, 94\% (34/36) had a 25$\mathrm{OH}$ vitamin D level $>20 \mathrm{ng} / \mathrm{ml}$ at M6. Of those who received two high doses of vitamin D3, a single dose both at baseline and M3, 91\% (49/54) exhibited a 25-OH vitamin D level of $>20 \mathrm{ng} / \mathrm{ml}$ at $\mathrm{M} 6$.

Differences between M3 and M0 compared to baseline values of 25-OH Vitamin D were available for 124 patients. There was a significant negative relation with a correlation coefficient $r=-0.3, p=0.0007$ : the lowest the baseline value, the highest the change after 3 months. Identical analysis was performed for differences between M6 and M3 25-OH vitamin D levels for 54 patients who received a second dose at 3 months. There was no more correlation between the differences and values 3 months before $(r=-0.11, p=0.43)$ (Fig. 3).

\section{Discussion}

We previously have demonstrated that hypovitaminosis D was highly prevalent in a population of Swiss rheumatology outpatients in autumn, and that classic oral daily supplementation with vitamin D3 was inefficient, with $75 \%$ of the patients on oral supplementation either deficient or insufficient in vitamin $\mathrm{D}$, probably secondary to poor adherence

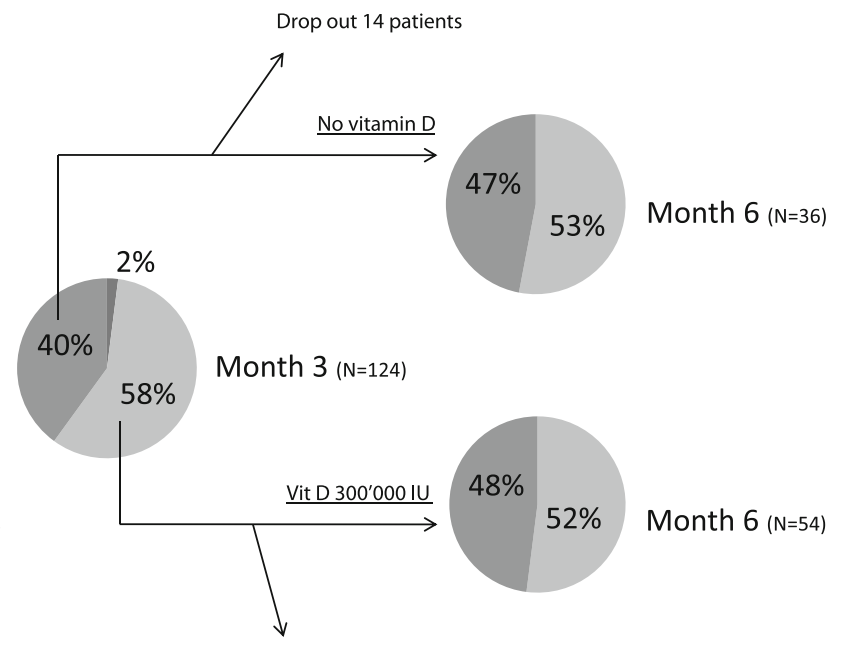

Drop out 18 patients 


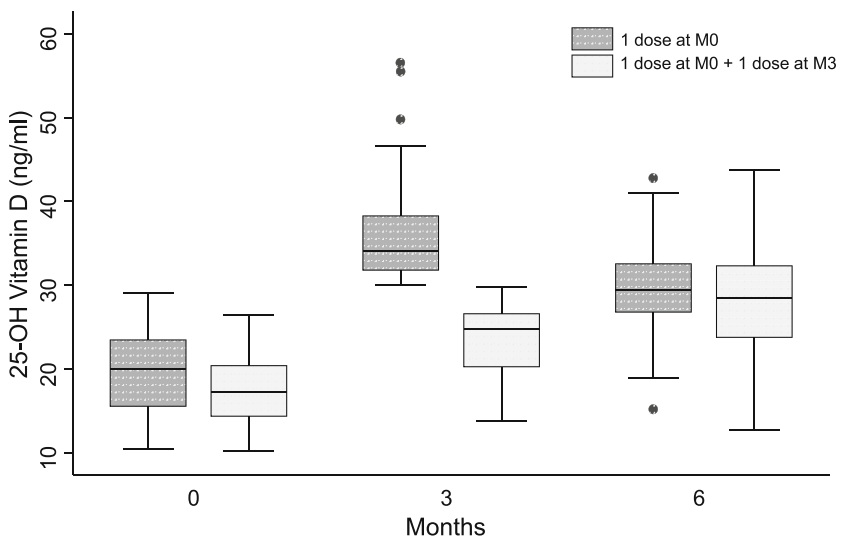

Fig. 2 Effect of high dose(s) of vitamin D3 on patients with insufficiency at 3 and 6 months

[13]. Another Swiss study demonstrated that less than 5\% of the elderly who recently had suffered from a hip fracture had vitamin D levels higher than the recommended $30 \mathrm{ng} / \mathrm{ml}$, and that about $70 \%$ of the European population is below this threshold [1].

As normalization of vitamin D levels appears to have clear benefits in the general population, we decided to evaluate the true effectiveness of supplementation with a single oral high dose of vitamin D3 (300,000 IU) to correct vitamin $\mathrm{D}$ insufficiency. This is a simple procedure that has gained wide-spread acceptance in Switzerland, despite the lack of any formal demonstration of its effectiveness. We began this study in 2009, before there was any significant controversy about the benefits of single high doses of vitamin D3 without calcium supplementation on fracture occurrence [16-18].

Even if approximately $50 \%$ of our patients achieved normal results at 3 months after a single high dose of vitamin D3, this still means that this level of supplementation was inadequate to correct insufficiency in the other half, even if the mean serum levels at month 3 were not much lower than the often recommended cut-off of $30 \mathrm{ng} / \mathrm{ml}$. On

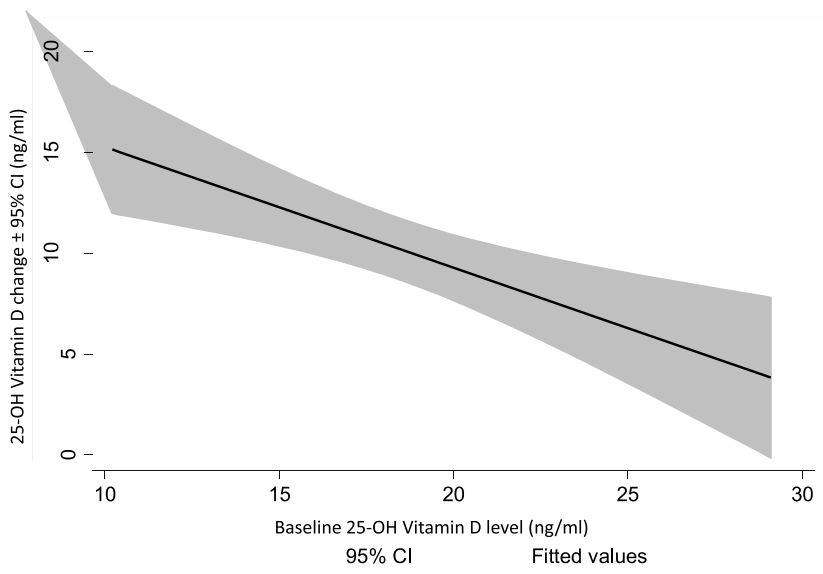

Fig. 3 Change in 25-OH vitamin D 3 months after the first dose the other hand, the $20 \mathrm{ng} / \mathrm{ml}$ cut-off recently recommended by the IOM was achieved by more than $80 \%$ and more than $90 \%$ of patients at months 3 and 6 , respectively.

Pharmacokinetic studies show that $25-\mathrm{OH}$ vitamin D levels peak at 7 to 21 days and, thereafter, decrease slowly $[19,20]$. It is known that any incremental increase in $25-\mathrm{OH}$ vitamin $\mathrm{D}$ is likely to be lower in those already replete prior to supplementation [21]. The results at 3 months are, interestingly, not very different from the levels attained on 800 IU of oral daily vitamin D3 in some studies, when patients are adherent to the prescription [22]. The patients who seemed to benefit more from supplementation were those with the lowest baseline levels. However, we were unable to predict normalization of vitamin D from baseline values.

We also were unable to predict the evolution of vitamin D levels after supplementation. About half of patients whose vitamin D levels had normalized by 3 months continued to exhibit normal levels at 6 months; meanwhile, by 6 months, a second prescription of 300,000 IU of oral vitamin D3, administered at M3, had normalized half of those insufficient at 3 months. These results are in congruence with the results of a recent study involving a smaller and older population of patients with vitamin D deficiency, where important individual variations were observed, despite the administration of a single high dose of 300,000 IU of vitamin D3 under supervision [23].

Our study had four main limitations. First, it is impossible to know for sure whether our patients really took their supplementation as prescribed and how they took it, as the administration was not supervised and adherence was not evaluated. Second, we lost $36 \%$ of our subjects over the course of follow-up ( $12 \%$ by 3 months). Third, the relevance of our results and the conclusion we can draw from them are also limited by the fact that we didn't measure other parameters such as calcium (could be suggested for safety reason) or parathyroid hormone (could help to determine the individual optimal 25-OH vitamin D level). Fourth, we didn't evaluate vitamin $\mathrm{D}$ level before 3 months, and if we cannot exclude correction of the insufficiency before that time point as it has been strongly supported by the literature $[17,21]$, the benefits would be nevertheless transient in this subgroup. Finally, it has been suggested that plasma concentrations of $25-\mathrm{OH}$ vitamin $\mathrm{D}$ may be decreased by inflammation and therefore less reliable in patient with systemic inflammatory disease. We could not address this problem with our study design. However, it appears unlikely that inflammation would be a major parameter in a treated population with mostly mild or absent inflammation [24].

On the other hand, this renders ours as a "real life" practical study that clearly demonstrates that a single high dose of vitamin D3 is insufficient to completely correct and avoid vitamin D insufficiency in this setting, if $30 \mathrm{ng} / \mathrm{ml}$ is 
the goal. In contrast, one or two oral boluses of 300,000 IU of vitamin D3 in autumn and winter was a good means of preventing the $25-\mathrm{OH}$ vitamin $\mathrm{D}$ nadir that usually is observed in the spring, since the average level was definitely higher than $20 \mathrm{ng} / \mathrm{ml}$. It also is possible that levels higher than $20 \mathrm{ng} / \mathrm{ml}$ (and lower than $30 \mathrm{ng} / \mathrm{ml}$ ) are adequate in a rheumatologic population (with or without osteoporosis), as recent reviews of evidence suggest [8]. Indeed, evidence for optimal bone health relates to level between 20 and $25 \mathrm{ng} / \mathrm{ml}$, higher levels mainly relate to muscle function.

Finally, as suggested in recent publications, daily vitamin D3 supplements, with or without co-administered calcium, are probably more physiological than single high doses of oral vitamin D3. Nevertheless, adherence often is low and the efficiency of such an approach appears limited, as we have observed in our population. There have been doubts that very high doses of vitamin D3 might be harmful. Indeed $100,000 \mathrm{IU}$ seems to be effective in reducing the occurrence of falls and fractures but 300,000 to 500,000 IU have been shown to actually increase this risk $[5,17,25]$. Other studies suggest that single oral doses of 300,000 IU of vitamin D3 are safe and more effective than $800 \mathrm{IU}$ per day to increase serum $25-0 \mathrm{H}$ vitamin $\mathrm{D}[26,27]$. Others suggest that vitamin D3 is more potent than vitamin D2 [28]. This area of controversy needs further evaluation and was not the purpose of our study. A single high dose of vitamin D3 is certainly appealing. However, the safety of such an approach still must be determined [17], as must its modalities of application, to ensure correction of the insufficiency in as large a percentage of patients as possible.

Conflict of interest There is no support from any organization for the submitted work; no financial relationships with any organizations that might have an interest in the submitted work in the previous three years, no other relationships or activities that could appear to have influenced the submitted work.

\section{References}

1. Bischoff-Ferrari HA et al (2008) Severe vitamin D deficiency in Swiss hip fracture patients. Bone 42(3):597-602

2. Chapuy MC et al (1992) Vitamin D3 and calcium to prevent hip fractures in the elderly women. N Engl J Med 327(23):1637-1642

3. Bischoff-Ferrari HA et al (2009) Fall prevention with supplemental and active forms of vitamin D: a meta-analysis of randomised controlled trials. BMJ 339:b3692

4. Bischoff-Ferrari HA et al (2009) Prevention of nonvertebral fractures with oral vitamin D and dose dependency: a meta-analysis of randomized controlled trials. Arch Intern Med 169(6):551-561

5. Trivedi DP, Doll R, Khaw KT (2003) Effect of four monthly oral vitamin D3 (cholecalciferol) supplementation on fractures and mortality in men and women living in the community: randomised double blind controlled trial. BMJ 326(7387):469
6. Crew KD et al (2009) High prevalence of vitamin D deficiency despite supplementation in premenopausal women with breast cancer undergoing adjuvant chemotherapy. J Clin Oncol 27 (13):2151-2156

7. Dawson-Hughes B et al (2010) IOF position statement: vitamin D recommendations for older adults. Osteoporosis Int 21(7):1151-1154

8. Rosen CJ (2011) Clinical practice. Vitamin D insufficiency. N Engl J Med 364(3):248-254

9. Sai AJ et al (2011) Relationship between vitamin D, parathyroid hormone, and bone health. J Clin Endocrinol Metab 96(3):E436E446

10. Rosen CJ, Gallagher JC (2011) The 2011 IOM report on vitamin D and calcium requirements for North America: clinical implications for providers treating patients with low bone mineral density. J Clin Densitom 14(2):79-84

11. Gallagher JC, Sai AJ (2010) Vitamin D insufficiency, deficiency, and bone health. J Clin Endocrinol Metab 95(6):2630-2633

12. Tang BM et al (2007) Use of calcium or calcium in combination with vitamin D supplementation to prevent fractures and bone loss in people aged 50 years and older: a meta-analysis. Lancet 370 (9588):657-666

13. Stoll D et al (2011) High prevalence of hypovitaminosis D in a Swiss rheumatology outpatient population. Swiss Med Wkly 141: w13196

14. Ross AC et al (2011) The 2011 report on dietary reference intakes for calcium and vitamin D from the Institute of Medicine: what clinicians need to know. J Clin Endocrinol Metab 96(1):53-58

15. Holick MF et al (2011) Evaluation, treatment, and prevention of vitamin D deficiency: an Endocrine Society clinical practice guideline. J Clin Endocrinol Metab 96(7):1911-1930

16. Sanders KM (2010) In older patients with hip fracture, extended physiotherapy reduces falls compared with standard physiotherapy, and high dose cholecalciferol reduces hospital readmissions compared with lower dose. Evid Based Med 15(5):144-145

17. Sanders KM et al (2010) Annual high-dose oral vitamin D and falls and fractures in older women: a randomized controlled trial. JAMA 303(18):1815-1822

18. Lai JK et al (2010) Hip fracture risk in relation to vitamin D supplementation and serum 25-hydroxyvitamin D levels: a systematic review and meta-analysis of randomised controlled trials and observational studies. BMC Public Health 10:331

19. Ilahi M, Armas LA, Heaney RP (2008) Pharmacokinetics of a single, large dose of cholecalciferol. Am J Clin Nutr 87(3):688-691

20. Wu F et al (2003) Efficacy of an oral, 10-day course of high-dose calciferol in correcting vitamin D deficiency. N Z Med J 116 (1179):U536

21. Bacon CJ et al (2009) High-dose oral vitamin D3 supplementation in the elderly. Osteoporosis Int 20(8):1407-1415

22. Krieg MA et al (1999) Effect of supplementation with vitamin D3 and calcium on quantitative ultrasound of bone in elderly institutionalized women: a longitudinal study. Osteoporosis Int 9(6):483-488

23. von Restorff C, Bischoff-Ferrari HA, Theiler R (2009) High-dose oral vitamin D3 supplementation in rheumatology patients with severe vitamin D3 deficiency. Bone 45(4):747-749

24. Reid D et al (2011) The relation between acute changes in the systemic inflammatory response and plasma 25 -hydroxyvitamin D concentrations after elective knee arthroplasty. Am J Clin Nutr 93 (5):1006-1011

25. Smith $\mathrm{H}$ et al (2007) Effect of annual intramuscular vitamin D on fracture risk in elderly men and women - a population-based, randomized, double-blind, placebo-controlled trial. Rheumatology (Oxford) 46(12):1852-1857

26. Leventis P, Kiely PD (2009) The tolerability and biochemical effects of high-dose bolus vitamin D2 and D3 supplementation in patients with vitamin D insufficiency. Scand J Rheumatol 38 (2):149-153 
27. Premaor MO et al (2008) The effect of a single dose versus a daily dose of cholecalciferol on the serum 25-hydroxycholecalciferol and parathyroid hormone levels in the elderly with secondary hyperparathyroidism living in a low-income housing unit. J Bone Miner Metab 26(6):603-608
28. Romagnoli E et al (2008) Short and long-term variations in serum calciotropic hormones after a single very large dose of ergocalciferol (vitamin D2) or cholecalciferol (vitamin D3) in the elderly. J Clin Endocrinol Metab 93(8):30153020 